\title{
Implications of the ISCHEMIA trial on the practice of surgical myocardial revascularization
}

Marc Ruel, MD, MPH, ${ }^{\mathrm{a}}$ Louise Y. Sun, MD, SM, ${ }^{\mathrm{a}}$ Michael E. Farkouh, MD, MSc, ${ }^{\mathrm{b}}$ and Mario F. Gaudino, MD, MEpi ${ }^{\mathrm{C}}$

Feature Editor's Introduction-A thorough understanding of the literature in regard to the management of coronary artery disease (CAD) is vital to the effective leadership of cardiovascular surgeons within the heart team. Several large seminal studies have contributed significantly to our knowledge base and similarly determined practice patterns and most effective management of our patients with single-vessel or multivessel CAD (ie, Bypass Angioplasty Revascularization Investigation, Syntax, STICH). Most recently, the International Study of Comparative Health Effectiveness With Medical and Invasive Approaches trial results were presented at the 2019 American Heart Association Scientific Sessions to further our understanding of the management of patients with stable ischemic heart disease. The findings were far-reaching and challenged our current management of patients with moderate and even severe ischemic heart disease, suggesting no benefit to revascularization over medical therapy in select patients. Although the findings are profound, there are several critical factors that should be considered in deciding on medical therapy over percutaneous coronary intervention or coronary artery bypass grafting. A deep understanding of the study outcomes and clinical variables to consider in choosing revascularization versus medical therapy is vital for cardiac surgeons to provide optimal survival and minimal morbidity to patients. Four experts in CAD and coronary revascularization, Drs Marc Ruel, Louise Sun, Michael Farkouh, and Mario Gaudino, were chosen to carefully interpret the outcomes of the International Study of Comparative Health Effectiveness With Medical and Invasive Approaches trial and implications for our patients. The article

From the aniversity of Ottawa Heart Institute, University of Ottawa, Ottawa, Canada; ${ }^{b}$ Peter Munk Cardiac Centre and Heart and Stroke Richard Lewar Centre, University of Toronto, Toronto, Canada; and ${ }^{\mathrm{c}}$ New York Presbyterian Hospital, Weill Cornell Medicine, New York, NY.

Received for publication June 1, 2020; revisions received July 16, 2020; accepted for publication July 17, 2020; available ahead of print Sept 9, 2020.

Address for reprints: Marc Ruel, MD, MPH, Division of Cardiac Surgery, University of Ottawa Heart Institute, 40 Ruskin St, Suite 3402, Ottawa, Ontario, Canada

(E-mail: mruel@ottawaheart.ca).

J Thorac Cardiovasc Surg 2021;162:90-9

$0022-5223 / \$ 36.00$

Copyright (c) 2020 by The American Association for Thoracic Surgery

https://doi.org/10.1016/j.jtcvs.2020.07.123

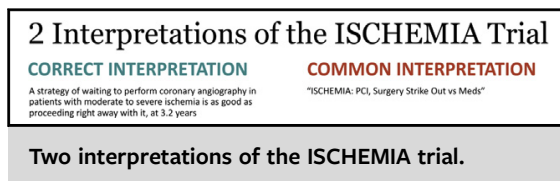

CENTRAL MESSAGE

The implications of the ISCHEMIA trial for cardiac surgeons are discussed.

This Invited Expert Opinion provides a perspec tive on the following papers: N Engl J Med. 2020;382(15):1395-1407. Moa1915922 N Engl J Med. 2020;382(15):1408-1419. https://doi.org/10.1056/NEJMoa1916370.

See Commentaries on pages 100 and 101.

provided by these thought leaders provides an excellent analysis of the trial and overall implications for managing $C A D$ in the modern era.

Pavan Atluri, MD

\section{DEFINING THE INDICATIONS FOR \\ MYOCARDIAL REVASCULARIZATION}

Although coronary artery bypass grafting (CABG) has been in existence since the mid-1960s, it was not until 1994 that its indications became more clearly established. At that time, a meta-analysis by Yusuf and colleagues ${ }^{1}$ was published, gathering individual data from 2649 patients with stable coronary artery disease (CAD) from 7 randomized controlled trials (RCTs) comparing CABG with optimal medical therapy (OMT). The authors found that patients who underwent $\mathrm{CABG}$ experienced a $39 \%$ mortality reduction at 5 years, despite a $37 \%$ incidence of crossover to CABG in the OMT group. ${ }^{1}$ The study identified, from statistically significant interactions, patients with left main (LM) stenosis, 3-vessel CAD, or left ventricular (LV) dysfunction as having greater survival benefit at 10 years than other subgroups, which led to the widely adopted indications for CABG that are still in use today. However, those significant interactions had not been present at the 5-year mark, and the benefits of CABG could simply have been 
considered not to be different among all subgroups. There was no correlation between the survival derived from CABG and the preoperative severity of angina, an important consideration in discussing the International Study of Comparative Health Effectiveness With Medical and Invasive Approaches (ISCHEMIA) trial. Patients in the metaanalysis by Yusuf and colleagues ${ }^{1}$ were relatively young (mean, $50.8 \pm 6.9$ years); $96.8 \%$ were male, and only $9.6 \%$ had diabetes at baseline.

As a result of this meta-analysis, now considered seminal, CABG is often performed for the purpose of prolonging life in the context of stable ischemic heart disease (SIHD). Indications for $\mathrm{CABG}$ have since extended to patients with an acute coronary syndrome, although not proven to be beneficial in that setting (Table 1). Additionally, CABG is effective at relieving angina, with nearly all comparisons having shown that it is superior to OMT or percutaneous coronary interventions (PCIs) for that purpose. ${ }^{2}$

Early trials of CABG versus OMT did not use modern pharmacologic interventions such as statins, inhibitors of the renin-angiotensin-aldosterone axis, or newer antiplatelet agents, all of which have been demonstrated to reduce death and myocardial infarction (MI) in placebocontrolled trials. By the same token, techniques and secondary prevention after CABG in those early trials were commensurably poor. ${ }^{3}$ Over the next 2 decades, the benefits of CABG versus OMT did not get formally reevaluated in a large-scale randomized setting, except in the contexts of LV dysfunction, ${ }^{4}$ diabetes, ${ }^{5}$ and more recently as part of the ISCHEMIA, ${ }^{6}$ in which CABG was used in a minority of patients. An appraisal of the ISCHEMIA trial, in light of the evidence comparing CABG, PCI, and OMT over the last 20 years, forms the impetus for this article.

\section{STABLE ISCHEMIC HEART DISEASE: THE RISE AND PLATEAU OF THE STENTS}

Since Gruntzig performed the first PCI in 1977, the technology has drastically evolved from the expansion of bare metal stents in the late 1990s to the current routine use of second-generation drug-eluting stents (DESs). Concomitantly, the practice of PCI has moved beyond intervening on favorable or acute single-vessel lesions to addressing multivessel and LM CAD.

Amid initial widespread enthusiasm, a dozen early RCTs comparing CABG with PCI were gathered in a 2009 meta-analysis by Hlatky and colleagues. ${ }^{7}$ The authors pooled individual data from 7812 patients and did not show a difference in overall mortality at a median followup of 5.9 years $(15 \%$ and $16 \%$ mortality in the CABG vs PCI group, respectively; $P=.12)^{7}$ However, patients with diabetes or aged more than 65 years derived a survival benefit from CABG. In those early trials, patients had been selected on the basis of harboring PCI-favorable lesions. ${ }^{8} \mathrm{~A}$ stent was used $37 \%$ of the time, the burden of multivessel
CAD was low (also at $37 \%$ prevalence), and only $51 \%$ of the patients had significant proximal LAD stenosis.

Expectations ran high as DES and modern antiplatelet therapy developed, and interventional cardiologists could address more complex lesions with better outcomes. However, around 2007 reports emerged linking DES with an increased risk of stent thrombosis, and circumspection grew regarding the use of PCI in SIHD. ${ }^{9}$ The stage was set for 2 major clinical equipoises to concomitantly be investigated: (1) OMT, over which PCI had not been proven superior in SIHD, became a challenger to PCI; and (2) PCI, using better techniques and DES, became a challenger to CABG, including in the presence of diabetes, LM stenosis, or multivessel CAD. As a corollary, if PCI could be demonstrated noninferior to CABG for its well-established indications, its superiority over OMT in the context of SIHD could, in turn, be assumed. The future, however, did not turn out that way.

\section{OPTIMAL MEDICAL THERAPY CHALLENGES PERCUTANEOUS CORONARY INTERVENTION}

In 2007, the Clinical Outcomes Utilizing Revascularization and Aggressive Drug Evaluation (COURAGE) trial, performed in 2287 patients with SIHD, revealed that PCI did not reduce the risk of death or MI over OMT at a median of 4.6 years (Figure 1). These findings were confirmed in an extended 12-year follow-up of half the patients. ${ }^{10} \mathrm{PCI}$, however, relieved angina and prevented repeat revascularization to a greater extent than OMT. ${ }^{11}$ The trial had used bare metal stents almost exclusively. The mean LV ejection fraction was $61 \%$, and despite $70 \%$ of patients having multivessel CAD, only one-third had proximal LAD involvement.

The next year, the Bypass Angioplasty Revascularization Investigation 2 Diabetes (BARI 2D) trial, performed in 1605 patients with diabetes, found no hard end point (ie, death, MI, or stroke) benefit from the use of PCI over OMT. ${ }^{5}$ Likewise, PCI did not improve upon the results of OMT in a pooled analysis of patients with diabetes from the BARI 2D and COURAGE trials. ${ }^{12}$

Hopes were redirected toward fractional flow reserve (FFR) to guide the performance of PCI by intervening solely on lesions with FFR 0.80 or less and the use of newer stents. In 2009, the Fractional Flow Reserve versus Angiography for Multivessel Evaluation (FAME) trial revealed, in 1005 randomized patients, that FFR-guided PCI significantly reduced rates of death or MI by approximately $35 \%$ over conventional angiography-guided PCI. These encouraging results inspired the FAME-2 trial, in which 888 patients were randomized to FFR-guided PCI versus OMT. ${ }^{13}$ At 5 years, the composite primary end point of FAME-2 (death, MI, or urgent revascularization) had occurred less frequently in the PCI group than in the OMT group $(14 \%$ vs $27 \%$, respectively; $P<.001)$. This 
TABLE 1. Commonly held assumptions in the practice of myocardial revascularization with percutaneous coronary intervention or coronary artery bypass grafting

\begin{tabular}{|c|c|c|}
\hline Assumption & Caveat & Research needed \\
\hline $\begin{array}{l}\text { PCI improves hard end points } \\
\text { (death, MI) over OMT in } \\
\text { SIHD. }\end{array}$ & $\begin{array}{l}\text { Overextension, to PCI, of CABG vs OMT results. }{ }^{1} \text { No } \\
\text { direct evidence of hard end point benefit of PCI vs } \\
\text { OMT alone in nonacute setting, except subjective } \\
\text { angina and revascularization outcomes. FAME- } 2 \text { used } \\
\text { FFR-based PCI to achieve trend toward lower MI rates } \\
\text { than OMT. }{ }^{13} \text { No trial of PCI vs OMT in SIHD suggests } \\
\text { a mortality benefit. }\end{array}$ & $\begin{array}{l}\text { ISCHEMIA reports, after COURAGE, BARI 2D, } \\
\text { ORBITA, a lack of end point benefit for PCI vs } \\
\text { OMT. } 5,6,10,14 \text { ISCHEMIA-EXTEND (ie, 10-y results } \\
\text { of ISCHEMIA) could show benefit in the invasive- } \\
\text { strategy group, in which spontaneous MIs were less } \\
\text { frequent. Despite FAME-2, adoption of FFR-guided } \\
\text { PCI remains low. }\end{array}$ \\
\hline $\begin{array}{l}\text { For symptoms in patients with } \\
\text { SIHD, PCI is better than } \\
\text { medical therapy. }\end{array}$ & $\begin{array}{l}\text { Likely applies only in patients without diabetes. } \\
\text { Correlates with degree of ischemia (ORBITA) }{ }^{15} \text { or } \\
\text { angina (ISCHEMIA). }{ }^{29} \text { Subject to a placebo effect. }\end{array}$ & $\begin{array}{l}\text { A larger scale and longer duration placebo-controlled } \\
\text { trial (with masking) of PCI vs OMT is needed. }\end{array}$ \\
\hline $\begin{array}{l}\text { PCI is indicated in patients } \\
\text { with SIHD and severe LV } \\
\text { dysfunction. }\end{array}$ & $\begin{array}{l}\text { No large-scale trial has addressed the role of PCI in } \\
\text { patients with LV dysfunction. A recent observational } \\
\text { study shows CABG recipients to have markedly better } \\
\text { outcomes than PCI recipients. }\end{array}$ & $\begin{array}{l}\text { A modern RCT of CABG vs PCI vs OMT in patients with } \\
\mathrm{LV} \text { dysfunction is warranted. }\end{array}$ \\
\hline $\begin{array}{l}\text { CABG is indicated in patients } \\
\text { with acute coronary } \\
\text { syndrome. }\end{array}$ & $\begin{array}{l}\text { No RCT evidence supports the use of CABG in acute } \\
\text { coronary syndrome. Patients who benefit from CABG } \\
\text { in SIHD (ie, diabetes, moderate or more SYNTAX } \\
\text { score, LM CAD, LV dysfunction) might derive a } \\
\text { benefit. Patients are usually stabilized before CABG. }\end{array}$ & $\begin{array}{l}\text { A trial of CABG vs PCI in non-STEMI and select } \\
\text { settings (diabetes, high SYNTAX score) may be } \\
\text { warranted if early CABG risks can be minimized. }\end{array}$ \\
\hline $\begin{array}{l}\text { A sizable coronary vessel with } \\
\text { significant visual stenosis } \\
\text { should not be grafted at } \\
\text { CABG if its FFR value is } \\
>0.80 \text {. }\end{array}$ & $\begin{array}{l}\text { Overextension from the PCI literature including FAME } \\
\text { trials. FFR at CABG may yield subclinical effects on } \\
\text { composite arterial graft patency, but no known impact } \\
\text { on major adverse cardiac events. }\end{array}$ & $\begin{array}{l}\text { FFR-based rationale has spread to CABG without } \\
\text { clinical evidence that performing a graft on a sizable } \\
\text { stenosed vessel with FFR }>0.80 \text { is detrimental or not } \\
\text { indicated. }\end{array}$ \\
\hline $\begin{array}{l}\text { Stent thrombosis and graft } \\
\text { occlusion are comparable } \\
\text { outcomes (eg, Table } 1 \text { from } \\
\text { Stone and colleagues }{ }^{19} \text { ). }\end{array}$ & $\begin{array}{l}\text { The mortality risk of stent thrombosis is } 10 \text { - to }>100 \text {-fold } \\
\text { higher than CABG graft occlusion. }\end{array}$ & $\begin{array}{l}\text { Surgical leadership in myocardial revascularization trials } \\
\text { may discourage use of such disparate comparisons. }\end{array}$ \\
\hline $\begin{array}{l}\text { CABG recipients fully } \\
\text { recover after 1-3 mo. }\end{array}$ & $\begin{array}{l}\text { Data suggest that recovery from CABG takes } \geq 6 \text { mo, } \\
\text { even in well-selected patients from RCTs. }{ }^{2}\end{array}$ & $\begin{array}{l}\text { Minimally invasive multivessel CABG may accelerate } \\
\text { postoperative recovery. }{ }^{37}\end{array}$ \\
\hline $\begin{array}{l}\text { Subgroup analyses in trials or } \\
\text { meta-analyses are often } \\
\text { useful. }\end{array}$ & $\begin{array}{l}\text { Subgroup analyses, even from large, carefully conducted } \\
\text { RCTs, are underpowered and generally prone to } \\
\text { spurious effects. }\end{array}$ & $\begin{array}{l}\text { Only subgroup analyses that are prespecified and with a } \\
\text { statistically significant test for interaction should be } \\
\text { reported. Others can result in type I error, type II error, } \\
\text { or overgeneralization. }\end{array}$ \\
\hline $\begin{array}{l}\text { The SYNTAX score was an a } \\
\text { priori hypothesis that has } \\
\text { broad impact. }\end{array}$ & $\begin{array}{l}\text { SYNTAX score boundaries were derived from post hoc } \\
\text { analyses. Subsequent data have shown the SYNTAX } \\
\text { score to not correlate well with benefits of CABG over } \\
\text { PCI, eg, in patients with diabetes and multivessel } \\
\text { CAD, or in low SYNTAX score group of } \\
\text { NOBLE. }\end{array}$ & $\begin{array}{l}\text { Further research is needed on the role of the SYNTAX } \\
\text { and other CAD severity scores. }\end{array}$ \\
\hline $\begin{array}{l}\text { PCI and CABG are equivalent } \\
\text { modalities for LM disease. }\end{array}$ & $\begin{array}{l}\text { Refuted by recent data from the EXCEL and NOBLE } \\
\text { trials. }{ }^{18,19,24} \text { SYNTAXES analysis has important } \\
\text { caveats. }{ }^{20} \text { Results in LM CAD may not be } \\
\text { distinguishable from the overall benefits of } \\
\text { CABG vs PCI. }{ }^{38}\end{array}$ & $\begin{array}{l}\text { More research is necessary, including whether multiple } \\
\text { arterial grafts should be used in nonflow limiting LM } \\
\text { CAD. }\end{array}$ \\
\hline $\begin{array}{l}\text { Heart teams should include } \\
\text { cardiac surgeons and } \\
\text { interventional } \\
\text { cardiologists. }\end{array}$ & $\begin{array}{l}\text { ISCHEMIA suggests that OMT experts also should serve } \\
\text { on heart teams. }{ }^{6}\end{array}$ & $\begin{array}{l}\text { ISCHEMIA-EXTEND will provide a more complete } \\
\text { picture. CABG should always be accompanied by } \\
\text { high-quality OMT. }\end{array}$ \\
\hline
\end{tabular}


TABLE 1. Continued

\begin{tabular}{ccc}
\hline Assumption & Caveat & Research needed \\
\hline PCI and CABG cause & Both PCI and CABG likely carry a considerable placebo & Interpretation of open-label trials with subjective \\
minimal placebo effect. & effect. ${ }^{14} \mathrm{CABG}$ additionally generates a nonspecific & outcomes, such as angina or revascularization for \\
& inflammatory response that may temporarily induce & symptoms, must account for these limitations. \\
& collateral formation and angiogenesis. & \\
\hline
\end{tabular}

PCI, Percutaneous coronary intervention; $M I$, myocardial infarction; $O M T$, optimal medical therapy; SIHD, stable ischemic heart disease; $C A B G$, coronary artery bypass grafting; $F A M E$, Fractional Flow Reserve versus Angiography for Multivessel Evaluation; FFR, fractional flow reserve; ISCHEMIA, International Study of Comparative Health Effectiveness With Medical and Invasive Approaches; COURAGE, Clinical Outcomes Utilizing Revascularization and Aggressive Drug Evaluation; BARI 2D, Bypass Angioplasty Revascularization Investigation 2 Diabetes; ORBITA, Optimal Medical Therapy of Angioplasty in Stable Angina; $L V$, left ventricle; $R C T$, randomized controlled trial; $L M$, left main; $C A D$, coronary artery disease.

had prompted the Data and Safety Monitoring Board to stop the trial prematurely; however, end point differences were driven solely by urgent revascularization, which at 5 years occurred in $6.3 \%$ of the patients in the PCI group versus $21 \%$ in the OMT group. No significant difference in MI rates could be observed $(8.1 \%$ and $12 \%$, PCI vs OMT, respectively; hazard ratio, $0.66 ; 95 \%$ confidence interval [CI], 0.43-1.00), and the rates of death were equivalent
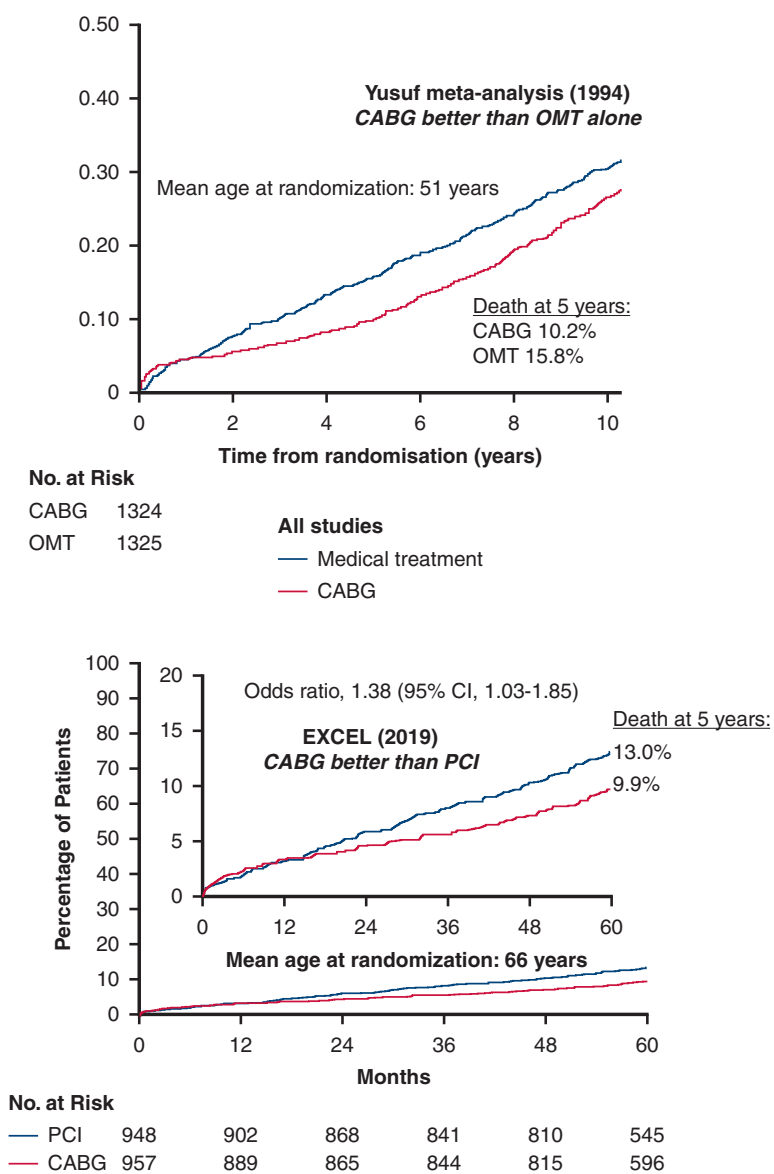

(5.1\% and 5.2\%, respectively; hazard ratio, $0.98 ; 95 \%$ CI, 0.55-1.8). ${ }^{1.3}$

It is important to realize that angina and repeat revascularization are subjective outcomes that may be affected by a lack of masking and a placebo effect after catheter-based or surgical revascularization (Table 1). This caveat provided the basis for the Objective Randomized Blinded Investigation with Optimal Medical Therapy 
of Angioplasty in Stable Angina (ORBITA) trial, which randomized 200 patients with anginal symptoms to undergo PCI with a DES or a placebo sham procedure. ${ }^{14}$ After enrollment, patients received 6 weeks of medication optimization. The primary end point was a change in treadmill exercise time between the groups before and after the procedure. Ultimately, ORBITA revealed no significant difference between the PCI and placebo groups in terms of increment in exercise time, time to 1-mm ST depression, or change in peak oxygen uptake. Symptoms also were not different between groups. As a subclinical effect, the degree of ischemia assessed by dobutamine stress echocardiography predicted the placebo-controlled efficacy of PCI on patient-reported angina. ${ }^{15}$

Therefore, in contrast to the meta-analysis by Yusuf and colleagues ${ }^{1}$ in 1994 that had established CABG as prolonging survival over OMT alone, all major PCI trials performed in SIHD failed to indicate that PCI was significantly better than OMT in preventing death or MI. This context provided the rationale for the ISCHEMIA trial.

\section{PERCUTANEOUS CORONARY INTERVENTION CHALLENGES CORONARY ARTERY BYPASS GRAFTING}

Around the same time, the SYNTAX, FREEDOM, NOBLE, and EXCEL trials concluded that CABG is associated with a $20 \%$ to $50 \%$ mortality decrease over PCI at 3 years and beyond, ${ }^{16,17}$ and with 2- to 3-fold greater freedom from spontaneous MI, ${ }^{18,19}$ even among patients selected most often according to their anatomic eligibility toward PCI. ${ }^{8}$ One area of controversy remains LM stenosis, for which some studies did not find a survival difference between $\mathrm{CABG}$ and $\mathrm{PCI}^{16,20}$; however, limitations of unknown crossover rates, controversial subgroup analyses, loss to follow-up, and markedly different OMT regimens between groups likely played a role over the long term. ${ }^{3,21}$ The recent controversy surrounding the EXCEL trial has relaunched the debate on LM CAD, with the European Association for Cardio-Thoracic Surgery rescinding its previous class I recommendation for the use of PCI in patients with LM with a SYNTAX score of 22 or lower. ${ }^{22}$ More detail on this has been published. ${ }^{8,23,24}$

The next major trial comparing PCI with CABG will be the FAME-3 study, which completed its 1500-patient enrollment in early $2020 .{ }^{25}$ In FAME-3, CABG was performed as per routine according to the coronary angiogram, whereas patients assigned to PCI had their FFR measured in each diseased vessel and underwent stenting using a second-generation DES only if the FFR value was 0.80 or less. The primary end point of FAME-3 is a composite of major adverse cardiac and cerebrovascular events including death, MI, repeat revascularization, and stroke by 1 year. As such, this composite outcome is likely to be noninferior at this short-term time point; analyses to a minimum of 5 years will be necessary considering recent findings from the EXCEL and NOBLE trials, in which the importance of adequate follow-up in RCTs comparing PCI with CABG was once more demonstrated. ${ }^{18,19}$

In the special context of diabetes and multivessel CAD, CABG has repeatedly been shown to be superior to PCI for the end points of death, MI, or stroke. ${ }^{25}$ An indication for CABG over PCI therefore exists in patients with diabetes who are good surgical candidates if 2-vessel or 3 -vessel CAD is present and irrespective of the SYNTAX score. ${ }^{17,23,26}$

\section{RATIONALE AND DESIGN OF THE ISCHEMIA TRIAL}

Previous RCTs indicated that PCI in the context of SIHD may prevent revascularization and improve symptoms over OMT alone, but with no impact on preventing death or MI. This stands in contrast with the established benefits of CABG over OMT. ${ }^{1}$ Consequently, the ISCHEMIA trial was designed to address whether an initial invasive strategy (angiogram followed by routine revascularization with PCI or CABG) plus OMT versus an initial conservative strategy of OMT alone without angiogram reduces the rates of a composite of death from cardiovascular causes, MI, or hospitalization for unstable angina, heart failure, or resuscitated cardiac arrest. ${ }^{27}$ ISCHEMIA's hypothesis was not whether revascularization improves outcomes, which remains a question that clinicians still want answered, because coronary angiography is a common diagnostic procedure that poses relatively few risks. Because an invasive versus conservative strategy was the assigned initial approach in the ISCHEMIA trial, subsequent angiography and revascularization, which took place in more than $20 \%$ of patients in the conservative-strategy group, or not undertaking angiography or revascularization in the invasive-strategy group, which also occurred in approximately $20 \%$, were not categorized as what another trial would have considered as high dilution and crossover rates.

The ISCHEMIA trial included patients with SIHD and moderate to severe ischemia on noninvasive stress testing. Eligible patients could experience no worse than Canadian Cardiovascular Society Class II angina; if class III angina was present, it had to be stable in severity and not of recent onset. In addition, patients needed to fulfill one of the following criteria: $10 \%$ or more of the myocardium with ischemia on nuclear perfusion imaging or $12 \%$ or more by cardiac magnetic resonance; 3 or more of 16 segments with stress-induced severe hypokinesis or akinesis on echocardiography or cardiac magnetic resonance; or new STsegment depression on exercise testing alone, provided that additional eligibility criteria were met. ${ }^{27}$ Patients with a history of $50 \%$ or more LM stenosis on prior coronary computed tomography angiography (CCTA) or cardiac catheterization were excluded. Also ineligible were patients 
with no obstructive CAD (ie, $<50 \%$ stenosis in all major epicardial vessels) on prior CCTA or catheterization; patients with a coronary anatomy unsuitable for PCI or CABG; and patients with an unacceptably high level of angina despite maximal medical therapy. One misconception is that all patients in ISCHEMIA underwent CCTA to rule out LM CAD; in fact, $27 \%$ of patients in the trial did not undergo CCTA.

In ISCHEMIA, the type of revascularization, (ie, PCI or CABG) was determined by the local heart team. Although the study protocol emphasized a number of principles, including use of CABG in patients with diabetes or according to SYNTAX score, CABG was likely underused as denoted next. The protocol also stipulated that every attempt should be made for the selected revascularization procedure to be performed within 1 week after randomization, with a target for all revascularization to have been completed within 30 days.

ISCHEMIA included both procedural and spontaneous MIs as part of its composite primary outcome. In accordance with virtually every other myocardial revascularization trial and in contrast to the EXCEL trial, ISCHEMIA's procedural MI definition used different biomarker thresholds for PCI and CABG, and used the Universal Definition of Myocardial Infarction. ${ }^{8}$

\section{MAIN FINDINGS OF THE ISCHEMIA TRIAL}

The ISCHEMIA trial randomized 5179 patients at 320 sites in 37 countries. The mean age of the patients was 64 years; $77 \%$ were male, and $42 \%$ had diabetes. A total of 2588 patients were randomized to the invasive strategy, and 2591 patients were randomized to the conservative strategy. Not all patients in the invasive-strategy group underwent coronary angiography; 205 patients $(7.9 \%)$ did not undergo it within 3 months of randomization, and 113 patients $(4.4 \%)$ never underwent angiography. An additional 421 patients $(16 \%)$ in the invasive-strategy group received angiography but did not receive revascularization. Overall, 534 of 2588 patients $(21 \%)$ in the invasive-strategy group did not undergo PCI or CABG. Among patients in the invasive-strategy group who had angiography, multivessel CAD was found in $71 \%$ of subjects $(1691 / 2371)$, including 2-vessel CAD in 32\% (751/2371) and 3-vessel in 40\% (940/2371). PCI was performed in 59\% (1524/2588) of patients in the invasive-strategy group, and CABG was performed in 20\% (530/2588) of patients.

Over a median of 3.2 years, ISCHEMIA reported 318 primary outcome events in the invasive-strategy group and 352 events in the conservative-strategy group. There were 145 deaths in the invasive-strategy group and 144 deaths in the conservative-strategy group (hazard ratio, 1.05 ; 95\% CI, 0.83-1.32) (Figure 1). At 5 years, the estimated cumulative major adverse cardiac event rate was $16.4 \%$ in the invasive-strategy group and $18.2 \%$ in the conservative-strategy group (difference, -1.8 percentage points; $95 \% \mathrm{CI},-4.7$ to 1.0 ). An early increased risk for primary outcome events in the invasive-strategy group was due to more procedural infarctions in early follow-up. Patients in the invasive-strategy group subsequently had fewer spontaneous MIs. The incidence of death from any cause was low and similar in the 2 groups. ISCHEMIA concluded that among patients with SIHD who had moderate or severe ischemia on stress testing, an initial invasive strategy, compared with an initial conservative strategy, did not reduce the rates of major adverse cardiac events.

In our view, $\mathrm{CABG}$, the only treatment known to surpass OMT in preventing death and MI in SIHD, was underused in ISCHEMIA, as is often the case worldwide. ${ }^{8}$ Although the precise number of patients in ISCHEMIA who met indications for CABG (ie, 2- or 3-vessel CAD with diabetes, nondiabetic patients with a SYNTAX score $\geq 23$ ) is not readily available, of the 1691 patients in the invasivestrategy group who had multivessel CAD, and of the 1071 patients with diabetes, only 530 patients received CABG. There were more patients in the invasive-strategy group who received no revascularization (ie, 534) than patients who underwent CABG (ie, 530).

After presentation of the ISCHEMIA trial at the November 2019 Scientific Sessions of the American Heart Association, headlines were quick to report the likes of "Ischemia: PCI, Surgery Strike Out vs Meds." ${ }^{28}$ Surely, methodologists and academics understand that ISCHEMIA was not about revascularization versus OMT, but rather about comparing 2 initial strategies (Figure 2). However, this correct interpretation is difficult to apply to a given patient with $\mathrm{CAD}$, including one who could have an indication for $\mathrm{CABG}$ and be a good candidate for it, but whose CAD extent has not been delineated by coronary angiography. As such, we believe that the who, when, and how of an initial conservative versus an initial invasive strategy, each with its $20 \%$ early transfer rate to the other strategy, bring a complex, difficult to generalize, and imperfectly applicable context around the exact nature of the ISCHEMIA trial intervention. Misinterpretations of the trial will continue to revolve around how "OMT was as good as revascularization with PCI or surgery." In our opinion, this common yet incorrect interpretation must consider that many patients in the invasive-strategy group had such minimal CAD that they did not require revascularization; that many patients in the initial conservative-strategy group rapidly transferred over to an invasive therapy; and that many patients in the invasive-strategy group did not receive the only mode of revascularization known to prevent death or MI over OMT alone (ie, CABG).

The health status outcomes in ISCHEMIA were published separately. ${ }^{29}$ Angina symptoms, dyspnea, and quality of life were compared before randomization, at months 1.5 , 


\section{Interpretations of the ISCHEMIA Trial CORRECT INTERPRETATION COMMON INTERPRETATION}

\author{
A strategy of waiting to perform coronary angiography in \\ patients with moderate to severe ischemia is as good as \\ proceeding right away with it, at 3.2 years

\section{PROS} \\ LARGE, smartly designed trial \\ NEW finding with regard to initial conservative strategy
}

\section{$\rightarrow$ CONS}

\begin{abstract}
WHAT prompts and WHEN should a move occur from an initial conservative to an invasive (angiography) approach, seen in $26 \%$ (with revascularization in $21 \%$ ) in the conservative-strategy group?

IN WHOM should a move between strategies occur? Do objective patient criteria (e.g., anatomy) trump subjective ones (i.e., symptoms, possibly including lack of placebo effect in the conservative-strategy group)?

HOW DOES ONE DO IT? Why was CABG, the only intervention known as better than OMT, rarely used in ISCHEMIA despite $2 / 3$ of patients having multivessel CAD and $42 \%$ having diabetes?

PATIENTS WERE MOVED from one ISCHEMIA strategy to another according to perceptions from the clinical era. Will new knowledge from ISCHEMIA impact the safe applicability of its 'initial conservative' strategy? What if an indication for CABG in a good candidate is missed, overlooked or dismissed?
\end{abstract}

"ISCHEMIA: PCI, Surgery Strike Out vs Meds"*

\section{PROS}

ALTHOUGH ERRONEOUS, this 'revascularization vs OMT' question is one that many view as central to the trial

DIFFICULT to know what an 'initial conservative' strategy means to the patient before us

\section{CONS}

ISCHEMIA did not address the above interpretation. There was no ' $\mathrm{PCl}$, Surgery group' versus 'Meds group'. If such a comparison had been the goal of ISCHEMIA, the 'PCI, Surgery' group would have suffered from an inordinately high incidence of:

DILUTION as $21 \%$ did not undergo revascularization in the invasive-strategy group

CROSSOVER as another $21 \%$ received revascularization in the conservative-strategy group, most often prior to a first event PE RFORMANCE BIAS as CABG -- the only modality known to best OMT in SIHD - was likely underutilized in ISCHEMIA

* https://www.medscape.com/viewarticle/921463 from November 16, 2019. Reference no. 27 in the article

FIGURE 2. Despite some misinterpretations, the ISCHEMIA trial did not investigate whether revascularization is better than OMT, but rather compared 2 initial treatment strategies.

3 , and 6, and every 6 months thereafter until termination of the trial. Notably, baseline Seattle Angina Questionnaire scores were more than 10 points higher (ie, more favorable) in the ISCHEMIA trial than in the COURAGE trial, and $35 \%$ of patients reported having no angina in the month before enrollment. Nevertheless, patients in the invasivestrategy group derived significant benefit from a symptoms point of view. Improvements with the invasive strategy were larger for patients with daily or weekly angina (8.5 points at 3 months and 5.3 points at 36 months), whereas patients with no angina at baseline had minimal to no incremental benefit. It should be emphasized that masking was not present in the ISCHEMIA trial, unlike in ORBITA, and that $10 \%$ of assessments were missing at any point in time.

Since publication of the ISCHEMIA trial, editorials and comments have also highlighted 3 other aspects:

1. ISCHEMIA shows a reversal in the balance of incident MI between the 2 strategies during the first 4 years of follow-up. The greater number of procedural MIs in the invasive-strategy group during the first 6 months of the trial was balanced by more spontaneous MIs in the conservative-strategy group. After 4 years, the incidence of the primary end point was numerically higher in the conservative-strategy group than in the invasivestrategy group. It is possible that ISCHEMIA ended before a substantial difference in favor of the invasive strategy emerged, which will hopefully be evaluated in the anticipated ISCHEMIA-EXTEND study (ie, at $\sim 10$-year follow-up).

2. The inclusion of many patients with mild or no angina, or with no proximal LAD disease, led many cardiac surgeons to view ISCHEMIA as a nonsurgical trial. On the contrary, ISCHEMIA included many patients with advanced CAD who could have undergone CABG. It is important to remember that the classic indications for $\mathrm{CABG}$ were derived from anatomic rather than functional criteria and that the severity of angina before CABG does not influence survival benefits. ${ }^{1}$ As such, cardiac surgeons frequently operate in patients with mild or no angina, or patients with diffuse CAD who exhibit primarily mid or distal LAD involvement. Surgeons should be knowledgeable about the ISCHEMIA trial and not dismiss it as nonsurgical.

3. ISCHEMIA may prompt clinicians to avoid myocardial stress imaging. In the trial, no relationship was observed between the severity of ischemia and all-cause mortality, 
and only a weak trend emerged for a relationship with 4year MI rates. Conversely, there was a strong relationship between anatomy and both mortality and MI, reported at the 2020 meeting of the American College of Cardiology. ${ }^{30}$ Although patients with greater anatomic burden had higher event rates, none of the groups, including the group with 3-vessel CAD or 2-vessel $\mathrm{CAD}$ involving the proximal $\mathrm{LAD}$, showed benefit from one treatment strategy over the other. We believe that the latter reflects the underuse of $C A B G$ in ISCHEMIA, because CABG could have played a key role toward preventing death or MI in patients with more anatomically advanced CAD in the invasivestrategy group.

ISCHEMIA-CHRONIC KIDNEY DISEASE AND THE EVEN RARER USE OF CORONARY ARTERY

\section{BYPASS GRAFTING}

In parallel with the main ISCHEMIA study, the ISCHEMIA-Chronic Kidney Disease trial randomly assigned 777 patients with advanced renal disease and moderate or severe ischemia on stress testing to the same initial conservative strategy or to an invasive strategy. ${ }^{31}$ Randomization allocated 389 patients to the conservative strategy and 388 patients to the invasive strategy at 118 sites in 30 countries. The median age of the patients was 63 years; $57 \%$ had diabetes, and $53 \%$ were receiving dialysis. Multivessel CAD was present in $51 \%$, involvement of the LAD was present in $57 \%$, and $27 \%$ of the patients had no obstructive CAD. Notably, $15 \%$ of the patients in the invasive-strategy group did not undergo coronary angiography, and among those who received it, another half did not proceed to revascularization, most commonly because of a lack of obstructive CAD.

At a median follow-up of 2.2 years, a primary outcome event occurred in 129 patients in the conservative-strategy group and 123 patients in the invasive-strategy group $(P=.95)$. The invasive strategy was associated with a higher incidence of stroke than the conservative strategy (hazard ratio, 3.8; 95\% CI, 1.5-9.3; $P=.004$ ) and with a higher incidence of death or initiation of dialysis (hazard ratio, $1.5 ; 95 \% \mathrm{CI}, 1.04-2.1 ; P=.03$ ). Notably, less than half (ie, 190/388) of the patients in the invasive-strategy group of ISCHEMIA-Chronic Kidney Disease underwent revascularization, of whom only 29 had CABG. These numbers confirm that ISCHEMIA did not compare revascularization versus OMT but rather 2 initial strategies and further support that the ISCHEMIA trials underused CABG, itself effective at preventing death or MI in patients with chronic kidney disease with advanced CAD. ${ }^{32}$

\section{HOW DOES ISCHEMIA IMPACT CARDIAC SURGERY PRACTICE?}

The ISCHEMIA trial proposes a paradigm shift and, in our opinion, reinforces the notion that CABG surgeons should be experts at understanding all stages of myocardial revascularization trials, from their rationale, design, conduct, interpretation, to their applicability. ${ }^{8}$ We provide the following considerations as to how ISCHEMIA might affect the practice of surgical myocardial revascularization in the future.

- Cardiac surgeons should thoroughly understand the indications for CABG, as well as the indications for PCI and for OMT alone, particularly in the context of SIHD. Table 1 denotes some unproven assumptions that are commonplace in myocardial revascularization practice.

- A medical therapy expert should participate in all Heart Team discussions to appropriately advocate for OMT, particularly for patients with SIHD who are unlikely to meet an indication for CABG. Reciprocally, cardiac surgeons should understand the caveats of the ISCHEMIA trial and the reasons as to why it was improbable that the trial would reveal a benefit in patients assigned to the invasive strategy.

- Cardiac surgeons should continue to advocate for patients who may have an indication for CABG and for the importance of performing coronary angiography toward identifying those patients. In the post-ISCHEMIA world, unless one believes that the results of PCI in SIHD are worse than OMT alone (which previous data do not suggest), the latest results from the FREEDOM, NOBLE, and EXCEL trials, as well as in patients with severely reduced LV ejection fraction, support that an indication for CABG should be ruled out in every ISCHEMIA-type patient, because the pursuit of CABG when indicated may be vitally important for a given patient and his/her family. ${ }^{18,19,33,34}$

- OMT is paramount in patients undergoing CABG. Its strong adoption decreases the need for revascularization and makes the results of CABG incrementally better than those of other modalities, thereby benefitting patients with severe CAD. ${ }^{21}$ The positive effects of OMT after $\mathrm{CABG}$ may be as important as those derived from a second arterial graft. ${ }^{3}$

- More than ever, surgical leadership is needed when appropriately designing, performing, and interpreting myocardial revascularization trials. Because CABG remains the safest and most durable therapy for severe CAD, cardiac surgeons must be leaders at designing trials that do not dilute or misallocate, that put lesser emphasis, or that otherwise fail to take into account its demonstrated therapeutic effects. 


\section{CONCLUSIONS}

ISCHEMIA is an important trial for patients with advanced CAD who may have an indication and be a good candidate for CABG, as well as for cardiac surgeons and other cardiovascular clinicians. Through cohort dilution, transfers from one strategy to another, and CABG underuse, the ISCHEMIA trial-if misinterpreted or overgeneralized-may inappropriately put into question the indications for CABG that have been shown to improve survival, freedom from MI, and symptoms beyond other modalities. Cardiac surgeons may not have been thoroughly informed about the ISCHEMIA trial, whereas discussions among cardiologists often revolved around procedural MI definitions, the magnitude of symptoms relief, and the usefulness of myocardial stress imaging. We believe that the issues raised in this article are important, because misinterpreting the ISCHEMIA trial as a neutral study suggesting that PCI or surgery is no better than OMT unjustifiably weakens the previously established indications for CABG and could result in lost lives.

It has metaphorically been stated that cardiac surgeons are "responsible for the skin and its contents." Increasing this responsibility to the next level implies that we thoroughly understand and co-lead the trials that affect the therapies for which we provide technical and content expertise and that repeatedly have been shown to save patients' lives.

\section{Conflict of Interest Statement}

The authors reported no conflicts of interest.

The Journal policy requires editors and reviewers to disclose conflicts of interest and to decline handling or reviewing manuscripts for which they may have a conflict of interest. The editors and reviewers of this article have no conflicts of interest.

\section{References}

1. Yusuf S, Zucker D, Peduzzi P, Fisher LD, Takaro T, Kennedy JW, et al. Effect of coronary artery bypass graft surgery on survival: overview of 10-year results from randomised trials by the coronary artery bypass graft surgery trialists collaboration. Lancet. 1994;344:563-70.

2. Kulik A. Quality of life after coronary artery bypass graft surgery versus percutaneous coronary intervention: what do the trials tell us? Curr Opin Cardiol. 2017;32:707-14.

3. Kulik A, Ruel M, Jneid H, Ferguson TB, Hiratzka LF, Ikonomidis JS, et al. Secondary prevention after coronary artery bypass graft surgery: a scientific statement from the American Heart Association. Circulation. 2015;131:927-64.

4. Velazquez EJ, Lee KL, Jones RH, Al-Khalidi HR, Hill JA, Panza JA, et al. Coronary-artery bypass surgery in patients with ischemic cardiomyopathy. $N$ Engl J Med. 2016;374:1511-20.

5. Group BDS, Frye RL, August P, Brooks MM, Hardison RM, Kelsey SF, et al. A randomized trial of therapies for type 2 diabetes and coronary artery disease. N Engl J Med. 2009;360:2503-15.

6. Maron DJ, Hochman JS, Reynolds HR, Bangalore S, O'Brien SM, Boden WE, et al. Initial invasive or conservative strategy for stable coronary disease. N Engl J Med. 2020;382:1395-407.

7. Hlatky MA, Boothroyd DB, Bravata DM, Boersma E, Booth J, Brooks MM, et al. Coronary artery bypass surgery compared with percutaneous coronary interventions for multivessel disease: a collaborative analysis of individual patient data from ten randomised trials. Lancet. 2009;373:1190-7.

8. Ruel M, Falk V, Farkouh ME, Freemantle N, Gaudino MF, Glineur D, et al. Myocardial revascularization trials. Circulation. 2018;138:2943-51.

9. Lagerqvist B, Carlsson J, Frobert O, Lindback J, Schersten F, Stenestrand U, et al. Stent thrombosis in Sweden: a report from the Swedish coronary angiography and angioplasty registry. Circ Cardiovasc Interv. 2009;2:401-8.

10. Sedlis SP, Hartigan PM, Teo KK, Maron DJ, Spertus JA, Mancini GB, et al. Effect of PCI on long-term survival in patients with stable ischemic heart disease. $N$ Engl J Med. 2015;373:1937-46.

11. Boden WE, O'Rourke RA, Teo KK, Hartigan PM, Maron DJ, Kostuk WJ, et al. Optimal medical therapy with or without PCI for stable coronary disease. $N$ Engl J Med. 2007;356:1503-16.

12. Mancini GB, Farkouh ME, Brooks MM, Chaitman BR, Boden WE, Vlachos H, et al. Medical treatment and revascularization options in patients with type 2 diabetes and coronary disease. J Am Coll Cardiol. 2016;68:985-95.

13. Xaplanteris P, Fournier S, Pijls NHJ, Fearon WF, Barbato E, Tonino PAL, et al. Five-year outcomes with PCI guided by fractional flow reserve. N Engl J Med. 2018;379:250-9.

14. Al-Lamee R, Thompson D, Dehbi HM, Sen S, Tang K, Davies J, et al. Percutaneous coronary intervention in stable angina (ORBITA): a double-blind, randomised controlled trial. Lancet. 2018;391:31-40.

15. Al-Lamee RK, Shun-Shin MJ, Howard JP, Nowbar AN, Rajkumar C, Thompson D, et al. Dobutamine stress echocardiography ischemia as a predictor of the placebo-controlled efficacy of percutaneous coronary intervention in stable coronary artery disease: the stress echocardiography-stratified analysis of ORBITA. Circulation. 2019;140:1971-80.

16. Head SJ, Milojevic M, Daemen J, Ahn JM, Boersma E, Christiansen EH, et al. Mortality after coronary artery bypass grafting versus percutaneous coronary intervention with stenting for coronary artery disease: a pooled analysis of individual patient data. Lancet. 2018;391:939-48.

17. Farkouh ME, Domanski M, Sleeper LA, Siami FS, Dangas G, Mack M, et al. Strategies for multivessel revascularization in patients with diabetes. $N$ Engl J Med. 2012;367:2375-84.

18. Holm NR, Makikallio T, Lindsay MM, Spence MS, Erglis A, Menown IBA, et al. Percutaneous coronary angioplasty versus coronary artery bypass grafting in the treatment of unprotected left main stenosis: updated 5-year outcomes from the randomised, non-inferiority NOBLE trial. Lancet. 2020;395:191-9.

19. Stone GW, Kappetein AP, Sabik JF, Pocock SJ, Morice MC, Puskas J, et al. Fiveyear outcomes after PCI or CABG for left main coronary disease. $N$ Engl J Med. 2019;381:1820-30.

20. Thuijs D, Kappetein AP, Serruys PW, Mohr FW, Morice MC, Mack MJ, et al. Percutaneous coronary intervention versus coronary artery bypass grafting in patients with three-vessel or left main coronary artery disease: 10-year follow-up of the multicentre randomised controlled SYNTAX trial. Lancet. 2019;394: 1325-34.

21. Ruel M, Kulik A. Suboptimal medical therapy after coronary revascularization: a missed opportunity. J Am Coll Cardiol. 2018;71:603-5.

22. Neumann FJ, Sousa-Uva M, Ahlsson A, Alfonso F, Banning AP, Benedetto U, et al. 2018 ESC/EACTS guidelines on myocardial revascularization. Eur Heart J. 2019;40:87-165.

23. Ruel M, Sun LY, Gaudino MF. The SYNTAX score according to diabetic status: what does it mean for the patient requiring myocardial revascularization? J Thorac Cardiovasc Surg. 2020;159:857-60.

24. Brophy JM. Bayesian Interpretation of the EXCEL trial and other randomized clinical trials of left main coronary artery revascularization. JAMA Intern Med. 2020;180:986-92.

25. Zimmermann FM, De Bruyne B, Pijls NHJ, Desai M, Oldroyd KG, Reardon MJ, et al. A protocol update of the fractional flow reserve versus angiography for multivessel evaluation (FAME) 3 trial: a comparison of fractional flow reserveguided percutaneous coronary intervention and coronary artery bypass graft surgery in patients with multivessel coronary artery disease. Am Heart J. 2019;214: $156-7$.

26. Verma S, Farkouh ME, Yanagawa B, Fitchett DH, Ahsan MR, Ruel M, et al. Comparison of coronary artery bypass surgery and percutaneous coronary intervention in patients with diabetes: a meta-analysis of randomised controlled trials. Lancet Diabetes Endocrinol. 2013;1:317-28.

27. Group ITR, Maron DJ, Hochman JS, O’Brien SM, Reynolds HR, Boden WE, et al. International study of comparative health effectiveness with medical and invasive approaches (ISCHEMIA) trial: rationale and design. Am Heart J. 2018;201:124-35 
28. Wendling P. Ischemia: PCI, surgery strike out vs meds. Medscape coverage from the American Heart Association (AHA) scientific sessions 2019. November 16, 2019. Available at: https://www.medscape.com/viewarticle/921463.

29. Spertus JA, Jones PG, Maron DJ, O’Brien SM, Reynolds HR, Rosenberg Y, et al Health-status outcomes with invasive or conservative care in coronary disease. $N$ Engl J Med. 2020;382:1408-19.

30. Reynolds HR. Relationships of ischemia severity and coronary artery disease extent with clinical outcomes in the ischemia trial. Presented at: the American College of Cardiology Virtual Annual Scientific Session Together With World Congress of Cardiology (ACC 2020/WCC); March 29, 2020.

31. Bangalore S, Maron DJ, O'Brien SM, Fleg JL, Kretov EI, Briguori C, et al. Management of coronary disease in patients with advanced kidney disease. $N$ Engl $J$ Med. 2020;382:1608-18.

32. Hayatsu Y, Ruel M, Sun LY. Renal insufficiency and severe coronary artery disease: should coronary artery bypass grafting, off-pump coronary artery bypass grafting or percutaneous coronary intervention be performed? Curr Opin Cardiol. 2019;34:645-9.

33. Sun LY, Gaudino M, Chen RJ, Bader Eddeen A, Ruel M. Long-term outcomes in patients with severely reduced left ventricular ejection fraction undergoing percutaneous coronary intervention vs coronary artery bypass grafting. JAMA Cardiol. 2020;5:631-41.

34. Farkouh ME, Domanski M, Dangas GD, Godoy LC, Mack MJ, Siami FS, et al. Long-term survival following multivessel revascularization in patients with diabetes: the FREEDOM follow-on study. J Am Coll Cardiol. 2019;73: 629-38.

35. Spadaccio C, Glineur D, Barbato E, Di Franco A, Oldroyd KG, BiondiZoccai G, et al. Fractional flow reserve-based coronary artery bypass surgery: current evidence and future directions. JACC Cardiovasc Interv. 2020;13: 1086-96.

36. Glineur D, Grau JB, Etienne PY, Benedetto U, Fortier JH, Papadatos S, et al Impact of preoperative fractional flow reserve on arterial bypass graft anastomotic function: the IMPAG trial. Eur Heart J. 2019;40:2421-8.

37. Guo MH, Wells GA, Glineur D, Fortier J, Davierwala PM, Kikuchi K, et al. Minimally Invasive coronary surgery compared to sternotomy coronary artery bypass grafting: the MIST trial. Contemp Clin Trials. 2019;78:140-5.

38. Freemantle N, Ruel M, Gaudino MFL, Pagano D. On the pooling and subgrouping of data from percutaneous coronary intervention versus coronary artery bypass grafting trials: a call to circumspection. Eur J Cardiothorac Surg. 2018;53:915-8.

Key Words: clinical trials, coronary angiography, coronary artery bypass grafting, coronary artery disease, observational studies, optimal medical therapy, outcomes, percutaneous coronary intervention, surgery 